\title{
Effective Strategies to Combat High Suicides and Trauma Among American Veterans
}

\section{Ronald D Hester*}

Department of Health Services Administration, Nicole Wertheim College of Nursing and Health Sciences, Florida International University, Miami, Florida, USA

*Corresponding author: Ronald D. Hester, Assistant Clinical Professor, Department of Health Services Administration, Nicole Wertheim College of Nursing and Health Sciences, Florida International University, Miami, Florida, USA, Tel: +1305-348-2000; E-mail: rhester@fiu.edu

Rec date: October 31, 2017; Acc date: November 13, 2017; Pub date: November 15, 2017

Copyright: (c) 2017 Hester RD. This is an open-access article distributed under the terms of the creative commons attribution license, which permits unrestricted use, distribution, and reproduction in any medium, provided the original author and source are credited.

\section{Commentary}

This article provides a description of the evidence - based treatment procedures that have proven effective to reduce self-harm and suicides among American veterans. The article suggest that an assessment is required using the Columbia Severity Rating Scale (2003) developed by Columbia University to assess the needs of returning veterans who have participated in combat and are experiencing physical and mental trauma. This article describes the necessary treatment procedures to assist returning veterans to receive a holistic approach to address their physical and mental conditions once they return home from intensive combat. Hopefully, a number of USA Veteran Medical Centers will consider this treatment, to assist returning veterans who are experiencing depression, PTSD and other mental health issues.

Our returning soldiers from deployment in Afghanistan, Iraq and Syria are often exhibiting episodes of physical and mental trauma [1]. This problem is very prevalent and is proportional to the increasing numbers of veterans, whom have fought in these combat zones. Most of these veterans are very patriotic Americans and reside in small rural communities through- out Mid-Western States. As a result, when these veterans return home to Rural America, they feel isolated, are often unemployed and some have become addicted to various substances such as opioids. This problem is due in large part because the trauma they've experienced overseas has not been dealt with from their conscious mind.

Rural America often has very isolated communities, where the main economy has been depleted [2]. The returning veteran is often unemployed, feeling isolated from their friends at home, detached from their teams still in the fight, and are, in many cases, experiencing the physical trauma of being severely wounded. Others must deal with problems such as a now dysfunctional marriage, homelessness and addiction to drugs.

In mid-September, President Trump signed a new law called The V.A. Choice and Quality Employment Act of 2017. This new federal law is appropriated to the Veterans Choice program at each of the VA Medical Centers nationwide. The Centers now have access to additional federal funds to upgrade their facilities, increase mental health capacity at the Centers, develop relations with the private sector mental health systems to address the problem of veteran's suicides in each of these facilities.

Recent data from the Office of Suicide Prevention, USA Department of Veteran Affairs, has shown the problem of veterans inflicting selfharm to themselves has increased not only by male veterans, but also among returning female veterans [3]. The most recent data also identifies, that the problem of veteran self-harm and suicides is more prevalent in rural America than urban areas. As a result, efforts are now underway to develop effective strategies addressing the degree of physical and mental trauma in rural communities [4].

We at the Florida International University (FIU), Nicole Wertheim College of Nursing and Health Sciences have begun to develop an evidence -based strategy that relies on the use of the Columbia Suicide Severity Rating Scale, to identify those returning veterans at the greatest risk for self-harm due to the trauma related to injury, depression, PTSD and the use of addictive substances [5]. The treatment strategy below was developed is based upon existing evidence - based research, which has proven that together a holistic approach to address the problem of veteran's self - harm and suicide can be addressed in the clinical centers at most VA Medical Centers nationwide.

The treatment strategy involves the following:

- Establish a patient navigator team, to perform outreach in the community, to assist more veterans to gain access to mental health and social supportive services. Especially those veterans who live in the community, feel depressed and have contacted the veterans crisis line for support or assistance [6].

- Establish a program to assist the veterans to gain access to music, art and animal therapy, to help reduce their stress once they have returned from combat [7].

- Reintroduce the veteran to a faith leader of their past faith, through the establishment of a faith counsel that will meet the veterans and help them to gain an understanding of their need to return to their faith and spirituality [8].

- Develop a series of training programs to improve their basic skill set. The army has identified that they have lowered their requirements to achieve the enlistment numbers for new recruits, so many of these individuals may need basic education skill development [9].

- Encourage veterans to return back to college or technical training schools to upgrade their skills and training in areas where they can find employment [10].

- Develop a series of programs to provide substance abuse treatment in the form of 12 step programs and detox programs to assist those veterans that have a substance crisis to obtain treatment [11].

- Implement a heart, body and soul program which places emphasis on exercise, fitness and nutritional supplements to improve the overall health of the returning veteran.

- Expand substance abuse and mental health treatment beds at many of the existing VA Medical Centers or contract with existing beds in the private sector to expand access to inpatient treatment services. 
Citation: Hester RD (2017) Effective Strategies to Combat High Suicides and Trauma Among American Veterans. J Trauma Treat 6: 403. doi:

Page 2 of 2

Each of the above programs can provide the comprehensive treatment that many returning veterans require to address the existing trauma in their lives, to become whole once again. The re-assessment of the Columbia suicide severity rating scale after each veteran receives the above treatment and supportive services, can hopefully identify how successful this program can help addresses the needs of veterans who recently return to small towns USA from combat.

\section{Acknowledgement}

Wish to thank Jewel Moseley Gray, Ph. D, RN. for her assistance in the development of this article.

\section{References}

1. Hester RD (2017) Lack of access to mental health services leads to high suicide rates for veterans. Int J Ment Health Syst 11: 47.

2. McCarthy JF, Blow FC, Ignacio RV, Ilgen MA, Austin KL, et al. (2012) Suicide among patients in the veteran's affairs health system: RuralUrban differences in rates, risk, and methods. Am J Public Health 102 111-117.
3. Veterans choice and quality employment Act of 2017. Public Law 115-146.

4. Suicide prevent and deaths (2016) Office of suicide Prevention, Department of Veteran Affairs, USA.

5. Columbia Seventy Rating Scale (2007) Columbia University, USA.

6. Miller M, Azrael D, Barber C, Mukamal K, Lawler E (2012) A call to link data to answer pressing questions about suicide risk among veterans. Am J Public Health 102: S20-S22.

7. Eaton KM, Messer SC, Garvey Wilson AL, Hoge CW (2006) Strengthening the validity of population- based suicide rates comparisons: an illustration using US military and civilian data. Suicide Life Threat Behav 36: 182-191.

8. Rozanov V, Carli V (2012) Suicide among war veterans. Int J Environ Res Public Health 9: 2504- 2519.

9. Sher L, Braquehais MD, Casas M (2012) Posttraumatic stress disorder, depression and suicide in veterans. Cleve Clin J Med 79: 92-97.

10. Sher L, Yehuda R (2011) Preventing suicide among returning combat veterans: a moral imperative. Mil Med 176: 601-602.

11. Ilgen MA, Bohnert AS, Ignacio RV, McCarthy JF, Valenstein MM, et al. (2010) Psychiatric diagnoses and risk of suicide in veterans. Arch Gen Psychiatry 67: 1152-1158. 